Revisión bibliográfica

Volumen 30(3):917-934. Septiembre-diciembre, 2019

e-ISSN 2215-3608, doi:10.15517/am.v30i3.34668

http://www.revistas.ucr.ac.cr/index.php/agromeso

\title{
Caña de azúcar y subproductos de la agroindustria azucarera en la alimentación de rumiantes ${ }^{1}$
}

\section{Sugar cane and by-products of the sugar agro-industry in ruminant feeding: A review}

\author{
Elizabeth Lagos-Burbano ${ }^{2}$,Edwin Castro-Rincón ${ }^{2}$
}

1 Recepción: 8 de octubre, 2018. Aceptación: 13 de febrero, 2019. Este trabajo formó parte del proyecto "Alternativas para la valorización de subproductos del proceso de elaboración de la panela con fines de alimentación animal y vegetal en el departamento de Nariño", financiado por el Sistema General de Regalias y ejecutado por la Corporación Colombiana de Investigación Agropecuaria (AGROSAVIA), Colombia.

2 Corporación Colombiana de Investigación Agropecuaria (AGROSAVIA). Nariño, Colombia. elagos@agrosavia.co, ecastro@agrosavia.co (https://orcid.org/0000-0001-9841-8242).

\section{Resumen}

Introducción. La caña de azúcar tiende a incrementar sus demandas de producción, considerando las perspectivas macroeconómicas a nivel mundial, debido a que el mercado tiene altos requerimientos de azúcar y melaza para la producción agroindustrial. Objetivo. El objetivo de esta revisión fue determinar el estado del arte en que se encuentra el uso del cultivo de caña de azúcar (Saccharum spp.) y los subproductos derivados de su proceso agroindustrial en la alimentación de rumiantes. Desarrollo. La industria de la caña de azúcar, como una especie proveedora de diferentes materias primas y subproductos resultantes de la transformación a panela o azúcar, presenta en la mayoría de los países dedicados al cultivo, ciertos problemas tecnológicos relacionados principalmente con el desperdicio y desaprovechamiento del bagazo, la cachaza y la cachaza deshidratada. Sin embargo, existen diversos estudios tendientes a demostrar la utilización de los subproductos en la alimentación animal, especialmente de rumiantes, mediante diversas tecnologías, que permiten mejorar la calidad y disponibilidad de los nutrientes en los mismos, para ser aprovechados por el animal. Conclusiones. Los subproductos de la caña de azúcar han sido utilizados para la elaboración de harinas, bloques y ensilajes, lo cual abre nuevos caminos en pro de un sistema de producción sostenible y amigable con el ambiente. Además, permiten hacer a un lado la concepción que se tenía en Colombia de que los subproductos agroindustriales eran de poco valor y su obtención generaba un impacto ambiental negativo.

Palabras clave: activadores ruminales, fibra, melaza, producción leche, peso vivo.

\begin{abstract}
Introduction. Sugarcane tends to increase its production demands, considering the world macroeconomic perspectives, due to the high demand of sugar and molasses for agro-industrial production. Objective. The objective of this review was to determine the state of the art about the use of sugarcane (Saccharum spp.) crop and byproducts derived from its agro-industrial processing in ruminant feeding. Development. The sugarcane industry, as
\end{abstract}


a species supplier of different raw materials and by-products resulting from the transformation to raw cane sugar or sugar, presents in the majority of countries dedicated to cultivation, some technological issues related mainly to the waste and wastage of bagasse, the cachaza and dehydrated cachaza. However, there are several studies showing the use of by-products in animal feed especially ruminants through various technologies, that improve the quality and availability of nutrients in them to be used by the animal. Conclusions. The sugarcane by-products have been used to make flours, silage, and supplementary blocks. This opens new paths for a sustainable and environmentally friendly production system. Furthermore, they allow to put aside the conception that was had in Colombia that the agroindustrial by-products were of low value and their obtaining generate a negative environmental impact.

Keywords: ruminal activators, fiber, molasses, milk production, live weight.

\section{Introducción}

La caña de azúcar (Saccharum spp.) es una planta de gran importancia en la economía de muchas regiones del mundo, por su versatilidad y capacidad de adaptación a diferentes condiciones ambientales. Los países productores de caña de azúcar están ubicados entre los $36,7^{\circ} \mathrm{LN}$ y $31,0^{\circ} \mathrm{LS}$, extendiéndose desde zonas tropicales a subtropicales y templadas, concentrando la mayor producción en América y Asia (CONADESUCA, 2015).

La producción de caña de azúcar es de 1900 millones de toneladas, en un área cosechada de 27 millones de hectáreas. Dicha producción se concentra principalmente en el continente americano con un 50,7 \%, seguido de Asia con un 40,9\%, África con un 5,9\% y Oceanía con un 2,5\%. Los diez principales países productores de caña de azúcar en orden descendente son: Brasil, India, China, Tailandia, Pakistán, México, Colombia, Australia, Indonesia y Estados Unidos (FAOSTAT, 2016). De todas las especies agrícolas, esta planta es la que convierte mayor energía solar en energía química (Mathier et al., 2013); sin embargo, solo se le atribuye valor comercial a un $24 \%$ de la materia seca acumulada durante el período vegetativo, el $76 \%$ restante lo constituyen los residuos resultantes de la fabricación del azúcar o la panela, tales como el cogollo, las hojas y pajas, el bagazo, la melaza y la cachaza (FEDEPANELA, 2012). La cantidad y el volumen de subproductos que se pueden aprovechar de la caña son altos, dado que por cada tonelada de panela se obtiene una tonelada de subproductos. Estos se pueden convertir en la materia prima para la elaboración de suplementos para la alimentación animal, los cuales pueden suministrarse en diferentes formas como ensilajes, harinas, bloques nutricionales y melote, el cual es producido por la deshidratación de la cachaza (Castaño et al., 2012). Los subproductos poseen un alto contenido de fibra, alta concentración de sacarosa y otros azúcares solubles (CENGICAÑA, 2014), pero bajos contenidos de proteína y minerales. Muchos de ellos han sido sometidos a tratamientos físicos, químicos y biológicos, con el fin de mejorar la disponibilidad de los nutrientes y por ende, su digestibilidad (Pachón et al., 2005). También han sido enriquecidos con fuentes de nitrógeno no proteico (urea) o con fuentes de proteína verdadera. Estudios sobre el desempeño de animales alimentados con subproductos resultantes de la industrialización de la caña, presentan nuevas perspectivas de investigación hacia un sistema de producción sostenible y amigable con el ambiente. Hoy en día se sabe que al darles un valor agregado se logra la reducción en los costos de alimentación, generados por la compra de materias primas que no se producen regionalmente y que compiten con la alimentación humana (Pachón et al., 2005).

El objetivo de esta revisión fue determinar el estado del arte en que se encuentra el uso del cultivo de la caña de azúcar y los subproductos derivados de su proceso agroindustrial en la alimentación de rumiantes (Figura 1). 


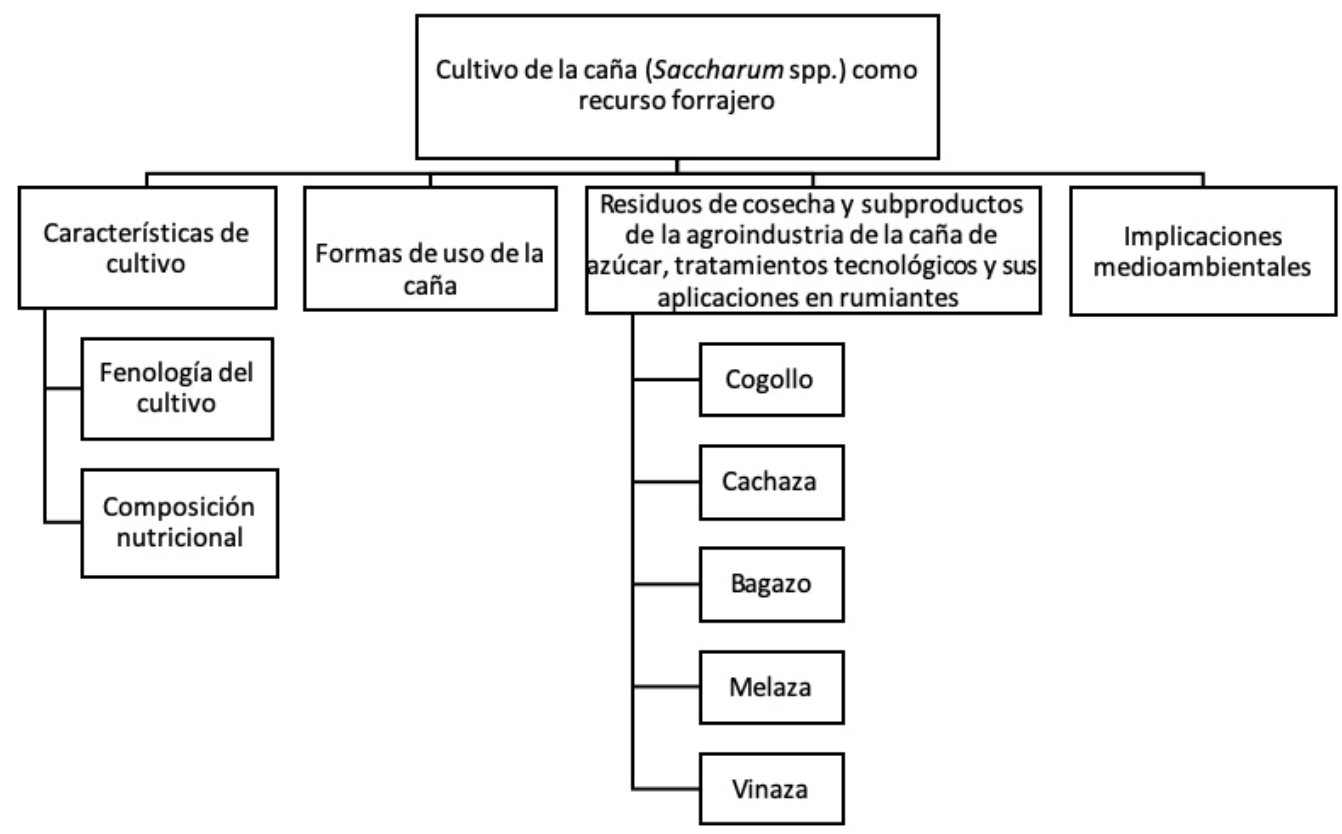

Figura 1. El cultivo de la caña (Saccharum spp.) como recurso forrajero en rumiantes. Colombia. 2017.

Figure 1. The cultivation of cane (Saccharum spp.) as a forage resource in ruminants. Colombia. 2017.

\section{Cultivo de la caña (Saccharum spp.) como recurso forrajero}

\section{Características del cultivo}

La caña de azúcar se caracteriza por su buena capacidad de adaptación a diversidad de suelos, climas, topografías, fertilidad y sistemas de producción, así como por su gran capacidad de producción de materia verde (más de $100 \mathrm{t}$ ha año ${ }^{-1}$ y materia seca por unidad de área (Ramírez et al., 2014). Al ser una planta C4, utiliza con mayor eficiencia el agua, pierde 277 moléculas de agua por molécula de $\mathrm{CO}_{2}$ fijada, por lo tanto, conserva más la humedad del suelo. Por su capacidad fotosintética y sus características fenotípicas, como la superficie foliar, capta eficientemente la energía solar para transformarla en biomasa (Bolufer, 2010; Aguilar, 2014).

En la etapa de madurez, se compone de aproximadamente 71,82\% de tallos molibles, 12,58 \% de cogollos, $8,7 \%$ de hojas y $6,9 \%$ de chulquines, los cuales pueden variar dependiendo de la variedad, edad y condiciones medioambientales. Todo este material vegetativo es aprovechado por el ganado bovino, sin el riesgo de perder sus características nutricionales cuando madura, por lo cual, constituye un forraje altamente disponible (Chavez, 2008).

Los azúcares totales (no reductores y reductores, sacarosa más otros azúcares) diluidos en el agua representan una fracción importante al ser una planta suculenta y turgente. También es alta en contenido de fibra, pero baja en proteína y minerales. Estudios realizados en diferentes países demuestran que, convenientemente suplementada, puede sostener buenas ganancias de peso y producciones de leche (Sierra, 1981; Gutierrez et al., 2014). 
En la búsqueda de mejores opciones de manejo y utilización de la caña, especialmente para la alimentación del ganado bovino, se le ha dado un valor relevante como componente de la dieta de los animales, para lo cual se emplean variedades forrajeras (Moreno, 2007). No obstante, para poder ser utilizada en la alimentación de rumiantes, se debe tener un amplio conocimiento de ciertos aspectos deseables como tipo de variedad, edad de corte y algunos indicadores de crecimiento, biométricas y de composición química que pueden ser utilizados como referencia para la selección y evaluación de genotipos con características forrajeras.

Dentro de los indicadores de crecimiento que se deben tener en cuenta están el área foliar, área foliar específica, peso foliar, tasa de crecimiento del cultivo, velocidad de producción de biomasa, duración del área foliar y duración de la biomasa; las características biométricas que se deben medir contemplan el número de tallos viables, número de tallos inviables, entrenudos totales, porcentaje de entrenudos descubiertos, diámetro del tallo y longitud del cogollo y, la valoración nutricional estará determinada por los contenidos de materia seca (MS), materia orgánica (MO), cenizas (CEN), proteína cruda (PC), fibra en detergente neutro (FDN), fibra en detergente ácido (FDA), nutrientes digestibles totales (NDT), $\mathrm{y}^{\circ} \mathrm{Brix}$, Pol (contenidos de sacarosa). Adicionalmente se deben medir los indicadores de madurez, comportamiento reproductivo de los animales que la consumen y, finalmente, la rentabilidad y aplicabilidad en los sistemas ganaderos, con el fin de garantizar la mayor producción a mínimos costos (Aranda et al., 2004; Moreno, 2007; Aguirre et al. 2010; Bastidas et al., 2010; Cordeiro et al., 2017; Fernández et al., 2018).

Al respecto, muchos países del trópico como por ejemplo Cuba, Venezuela, México, Colombia y otros países como la India y Argentina, han realizado estudios tendientes a evaluar variedades con potencial forrajero, basados en la medición de variables agronómicas, morfológicas, nutricionales, digestibilidad y de manejo, que pueden dar luces sobre las bondades de esta especie (López et al., 2003; Bastidas et al., 2010; Fernández et al., 2016a).

\section{Composición nutricional}

La caña de azúcar es rica en carbohidratos y una fuente energética por excelencia, pero su contenido en proteína es bajo (Cuadro 1), no supera el $5 \%$ de la materia seca, dependiendo del estado de madurez, la edad del

Cuadro 1. Composición nutricional de la caña de azúcar (Saccharum officinarum L). Colombia. 2017.

Table 1. Nutritional composition of sugarcane (Saccharum officinarum L). Colombia. 2017.

\begin{tabular}{|c|c|c|c|c|c|c|c|c|c|c|c|}
\hline Fracción & $\begin{array}{l}\text { MS } \\
(\%)\end{array}$ & $\begin{array}{c}\text { CEN } \\
(\%) \\
\end{array}$ & $\begin{array}{l}\text { EE } \\
(\%)\end{array}$ & $\begin{array}{l}\text { PB } \\
(\%)\end{array}$ & $\begin{array}{l}\text { ELN } \\
(\%)\end{array}$ & $\begin{array}{l}\text { FB } \\
(\%)\end{array}$ & $\begin{array}{l}\text { FDN } \\
(\%)\end{array}$ & $\begin{array}{c}\text { FDA } \\
(\%)\end{array}$ & $\begin{array}{l}\text { Ca } \\
(\%)\end{array}$ & $\begin{array}{c}\mathbf{P} \\
(\%)\end{array}$ & Autor \\
\hline Caña picada & 31,0 & - & - & 3,5 & - & - & - & - & - & - & Villar, 2010 \\
\hline Caña integral & - & - & - & 4,0 & - & - & 52,6 & 29,7 & 0,3 & 0,15 & $\begin{array}{c}\text { Albarracín et } \\
\text { al., } 2004\end{array}$ \\
\hline Caña molida & 98,0 & - & - & 1,5 & - & - & 44,8 & 35,2 & - & - & $\begin{array}{c}\text { Aguirre et al., } \\
2010\end{array}$ \\
\hline Forraje de caña & 34,3 & - & - & 3,9 & - & - & - & - & 0,4 & 0,09 & $\begin{array}{c}\text { Fundora et al., } \\
2007\end{array}$ \\
\hline Caña & 33,5 & - & - & 4,8 & - & - & 64,9 & 50,3 & 0,2 & 0,20 & $\begin{array}{l}\text { Rodríguez et } \\
\text { al., } 2009\end{array}$ \\
\hline Caña de azúcar & 29,0 & - & - & 2,4 & - & 30,8 & - & - & 0,2 & 0,10 & $\begin{array}{c}\text { García et al., } \\
2016\end{array}$ \\
\hline Caña de azúcar & 26,2 & $6,2-6,4$ & 1,9 & $2,0-5,4$ & 56,4 & 27,9 & 69,0 & 40,1 & $0,2-0,5$ & $0,09-0,14$ & Moreno, 2007 \\
\hline
\end{tabular}

MS: materia seca; CEN: ceniza; EE: extracto etéreo; PB: proteína bruta; ELN: extracto libre de nitrógeno; FB: fibra bruta; FDN: fibra en detergente neutro; FDA: fibra en detergente ácido; Ca: calcio; P: fósforo; MS: dry matter; CEN: ash; EE: etheric extract; PB: crude protein; ELN: nitrogen free extract; FB: crude fibre; FDN: neutral detergent fibre; FDA: acid detergent fiber; Ca: calcium; P: match. 
cultivo, la variedad y el clima (Moreno, 2007). Además, presenta un desequilibrio mineral y baja digestibilidad (20 $\%$ ), características que permiten clasificarla como forraje de regular calidad, por lo tanto, el suministro tiene que ir acompañado de una fuente de proteína y de minerales (Juárez et al., 2009).

$\mathrm{Al}$ evaluar la calidad forrajera de cinco cultivares de caña a diferentes edades de corte $(4,8,12$ y 16 meses) y ciclos de cosecha (plantilla y soca), se encontraron diferencias en el contenido de proteína cruda (PC) entre cultivares, siendo mayor la PC a los cuatro meses de edad y en el primer ciclo (plantilla). Para los mejores cultivares, a los cuatro meses de edad en plantilla la PC estuvo entre 9,11 y $7,72 \%$, a los ocho meses osciló entre de 6,03 y $4,1 \%$, a los doce meses entre 3,17 y $2,77 \%$ y a los dieciséis meses entre 3,63 y $1,92 \%$. Los valores de ceniza (CEN), calcio (Ca) y el fósforo $(\mathrm{P})$ mantuvieron un comportamiento similar, es decir, disminuyeron con la edad y ciclo de cosecha; sin embargo, la FDN presentó su mayor valor a los cuatro meses $(76,58$ y 79,9\%) en el primer ciclo (plantilla), la FDA mostró un comportamiento similar a la FDN, pero el contenido de FDN no difirió entre cultivares (López et al., 2003; Bastidas et al., 2010).

La composición química de la caña también depende de la interacción entre el cultivar, la edad del rebrote y la fracción de la planta (integral, cogollo y tallo), la PC es mayor para el cogollo (3,83 \%), seguido de la caña integral $(1,44 \%)$ y los tallos $(0,59 \%)$; la FDN es mayor para el cogollo (74 \%), intermedia para la caña integral $(54,13 \%)$ y menor para los tallos $(35,21 \%)$ debido a la cantidad de azúcares solubles en el contenido celular. Para el caso de las CEN, P y potasio (K), los contenidos dependen del cultivar, la edad de rebrote y de la fracción de la planta, pero en el contenido de materia seca (MS) intervienen la edad de rebrote y la fracción de la planta (López et al., 2003; Fernández et al., 2018).

El contenido nutricional y la producción de biomasa son factores condicionantes de la edad de corte adecuada para el consumo. La caña se puede cosechar entre los tres y cuatro meses de edad con el fin de aprovechar un forraje integral tierno y de buena calidad, debido a que presenta los mejores valores nutricionales, una mejor relación hoja/ tallo y una altura adecuada para la cosecha (Bastidas et al., 2010). También puede ser cosechada entre los ocho y doce meses de edad, dado la alta producción de biomasa, menor contenido de FDN, buen contenido de azúcares no reductores y reductores, con ${ }^{\circ}$ Brix que varían entre 12 y 16 y una humedad adecuada que facilita el proceso degradativo del alimento (Rodrigues, 1999; Mesén y Duran, 2011; Torres, 2011; Fernández et al., 2016b).

La edad de corte de la caña de azúcar estará en función de las necesidades del productor, las cuales estarán influenciadas por las condiciones de mercadeo, ambientales, número de cosechas que desee obtener y por disponibilidad de recursos. Su uso se puede ajustar a diferentes programas de alimentación, sin inconvenientes de tipo metabólico, cuando se utiliza a edades tempranas. En este sentido, se ha identificado que en los tallos de la caña cosechada en plantilla a los cuatro meses, la concentración de nitrato es 0,014 y $0,086 \%$, cuando se realizaron aplicaciones de 100 y $300 \mathrm{~kg} \mathrm{ha}^{-1}$ de $\mathrm{N}$ en el cultivo; estas concentraciones de nitrato están por debajo del nivel crítico considerado como peligroso para el ganado $(0,2 \%)$. Por lo tanto, a esta edad la caña puede ser utilizada en la alimentación animal (Ishikawa et al., 2007; Martínez y Sánchez, 2007).

Otro factor importante a considerar es la digestibilidad; en este sentido, mediante la técnica in situ, se han evaluado los cambios en la digestión de diferentes variedades de caña de azúcar integral y sus fracciones de FDN y FDA. Se sabe que existen diferencias significativas entre variedades, además, la digestibilidad de la caña integral es superior a la de las fracciones FDN y FDA, aunque, las tasas de digestión de la caña integral y de sus fracciones de fibra son bajas, condición que limita su utilización en la alimentación animal. Al comparar la digestibilidad in situ de las diferentes porciones de la caña (integral, tallos y cogollo), se ha encontrado que la digestibilidad a los 96 días de incubación es mayor para los tallos $(69,9 \%)$, seguido de la caña integral $(66,8 \%)$ y de los cogollos $(45,7 \%)$. Se ha determinado que la adición de enzimas fibrolíticas altera la estructura de la pared celular, por lo que se considera que esta puede mejorar la digestibilidad de la fibra de la caña de azúcar (López et al., 2003; Aranda et al., 2004).

Existe una relación inversa entre los mayores valores de la digestibilidad de la caña de azúcar integral (62\%) y los menores valores de la pared celular (42\%), debido a que los azúcares son los responsables de las altas cifras de 
digestibilidad. Se debe considerar que la relación de FDN: azúcares tiene que ser baja (menor a tres) para garantizar un adecuado consumo por parte de los rumiantes (Guerra, 2009).

El conocimiento de las variedades, manejo del cultivo, edad de corte y las demás variables anteriormente mencionadas, son indispensables, ya que definen en última instancia el verdadero valor del producto. No obstante, la opción más recomendada para el suministro es la caña integral, debido a que se aprovecha el total de la planta, no quedan residuos y presenta una adecuada digestibilidad y aceptación (Moreno, 2007).

\section{Formas de uso de la caña de azúcar}

La caña de azúcar se puede mezclar con otras plantas, productos y subproductos de industria con el objeto de mejorar los contenidos de materia seca, proteína, energía y minerales, y compensar las deficiencias de nutrientes que presenta (Martín, 2005). La mayoría de los estudios están enfocados a la adición de urea como fuente de nitrógeno no proteico, debido a la posibilidad que tienen los rumiantes de utilizarla de forma lenta, lo que posibilita el suministro estable de un grupo de nutrientes que mejoran el funcionamiento de la microflora ruminal, logrando mayor degradabilidad de los alimentos voluminosos (Garriz y López, 2002; Sousa et al., 2015).

Se ha utilizado también la caña de azúcar con otras fuentes alimenticias, tales como el concentrado, maíz y otros forrajes. En un estudio donde se suministró a los animales $1 \mathrm{~kg}$ de forraje de maíz y 6 o $10 \mathrm{~kg}$ de caña de azúcar, la ganancia media diaria de peso (622 vs $573 \mathrm{~g}$ ) fue mayor con la inclusión de $10 \mathrm{~kg}$ de caña, garantizando un mejor comportamiento productivo en período de déficit hídrico (Irola et al., 2016). La calidad de la carne mejora cuando la caña de azúcar es incluida en los planes de alimentación; dietas constituidas por un $60 \%$ de caña y $40 \%$ de concentrado (harina de soya y maíz), comparada con heno costero, heno de yuca y subproducto deshidratado de guisantes más concentrado, no influyeron en el $\mathrm{pH}$, calorimetría, pérdida de cocción y fuerza cortante de la carne de cordero, pero sí tuvieron un efecto positivo en la longitud del sarcómero (46 $\mu \mathrm{m}$ ) y la longitud del músculo de Longissimus lumborum (40,16 $\mu \mathrm{m})$, atribuyéndole a la caña de azúcar la capacidad de reemplazar fuentes tradicionales de forraje para la estación seca (Menezes et al., 2016).

Se han encontrado ganancias de peso de $1,03 \mathrm{~kg}_{\text {animal }}{ }^{-1}$ día $^{-1}$ en toros mestizos Holstein, alimentados con forraje de caña de azúcar y concentrado (soya y maíz), con una mejoría en la conversión alimenticia (Rodríguez et al., 2013). Lo anterior se asocia a que la calidad de la proteína es un factor importante en el consumo de alimentos voluminosos en rumiantes, dado que las diferentes fuentes de proteína actúan como activadoras de la fermentación ruminal; no obstante, el consumo de materia seca como porcentaje del peso vivo no supera el 1,7 a 1,8 \%. Se

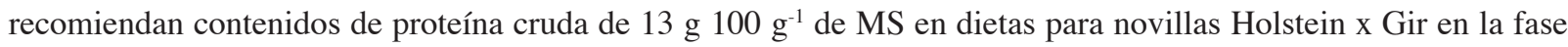
posterior al destete que consumen caña de azúcar, porque favorece la digestibilidad de la dieta y la disminución de las concentraciones de nitrógeno ureico en plasma y nitrógeno amoniacal (Soarez et al., 2012).

Existen estudios tendientes a resolver las deficiencias nutricionales que presenta la caña con la utilización de otros forrajes ricos en proteína como kenaf (Hibiscus cannabinus) y yuca (Manihot esculenta Cranz), con contenidos de PC de 23,4 y 24,5\%, respectivamente. En vacas Siboney con una producción de leche de $12 \mathrm{~kg}_{\text {día }}{ }^{-1}$ en 120 días de lactancia, a las cuales se les suministró $15 \mathrm{~kg}$ día $^{-1}$ de caña y tratamientos con $10 \mathrm{~kg}$ día $\mathrm{a}^{-1}$ de forraje fresco de kenaf, $10 \mathrm{~kg} \mathrm{día}^{-1}$ de forraje fresco de yuca y $150 \mathrm{~g}$ animal día ${ }^{-1}$ de urea, los resultados mostraron que los tratamientos con kenaf y yuca superaron al tratamiento con urea en 0,7 1 (García et al., 2016).

Con el fin de mejorar la digestibilidad de la fracción fibrosa y conservar el material picado, la caña de azúcar se ha tratado con productos químicos alcalinizantes como el hidróxido de sodio $(\mathrm{NaOH})$, hidróxido de potasio $(\mathrm{KOH})$, hidróxido de calcio $\left(\mathrm{Ca}(\mathrm{OH})_{2}\right)$, amoniaco anhídrido $\left(\mathrm{NH}_{3}\right)$ y óxido de calcio, estos agentes actúan parcialmente solubilizando la hemicelulosa e incrementando su digestión por los microorganismos, expanden las moléculas de celulosa, rompen los puentes de hidrógeno y aumentan la tasa de pasaje en el rumen. A la caña tratada con este tipo 
de sustancias se le conoce como caña hidrolizada (Kling et al., 2008; Pina et al., 2009; Ribeiro et al., 2009; Galindo y Rubio, 2011). Pese a que los resultados son positivos con $\mathrm{NaOH}$, este se ha evitado debido a la contaminación ambiental, exceso de sodio en la dieta, heces y orina de los animales, y especialmente por el daño potencial a la salud humana; por otro lado, el $\mathrm{NH}_{3}$ tiene desventajas, asociadas a su alto costo y baja potencia hidrolítica (Nussio et al., 2003).

$\mathrm{El} \mathrm{NaOH}$ se ha ido sustituyendo por el óxido de calcio $(\mathrm{CaO})$ o por cal hidratada $\left(\mathrm{Ca}(\mathrm{OH})_{2}\right)$, con un incremento en el contenido de la materia seca (10,8\% de MS con dosis $2,25 \%$ de CaO), DMS y minerales, mientras que los componentes de la pared celular disminuyen. Además, se ha detectado una estabilización de la temperatura, lo que permite el almacenamiento por períodos cortos de tiempo, contrario a lo que sucede con la caña no hidrolizada, en donde después de ser picada comienza a incrementar gradualmente la temperatura, debido a procesos fermentativos intensos (Ribeiro et al., 2009; Galindo y Rubio, 2011; Nogueira et al., 2012).

$\mathrm{Al}$ evaluar el rendimiento, la digestibilidad aparente total, la eficiencia de la síntesis microbiana y el balance de nitrógeno (BN) en novillas Holstein x Cebú alimentadas con caña de azúcar tratadas o no con $\mathrm{CaO}$ al $1 \%$ y diferentes niveles de concentrado $(0,0,5$ y $1 \%$ de peso corporal), se encontró que la caña tratada con $\mathrm{CaO}$ y después de $24 \mathrm{~h}$ de almacenada no cambió la digestibilidad, la ingesta de nutrientes, el balance de los compuestos nitrogenados y el desempeño animal, lo que sí sucede cuando se suministra hasta el $1 \%$ de concentrado en la dieta, aspecto que ocasionó una mayor ingesta y digestibilidad de los nutrientes, resultando en un mejor rendimiento animal (Kling et al., 2008).

En la década de los noventa se desarrolló en Cuba un método para la obtención de la sacharina, el cual consiste en cortar los tallos ( un buen desarrollo radicular y mayor concentración de los azúcares; se le adiciona una mezcla de 1,5 kg de urea, $0,5 \mathrm{~kg}$ de sal mineral completa y $0,75 \mathrm{~kg}$ de sulfato de amonio por cada $100 \mathrm{~kg}$ de caña. Esta mezcla se almacena bajo techo por un período de $15 \mathrm{~h}$, después del cual ya puede ser suministrado a los animales (Ávila et al., 2017). La sacharina también se puede preparar seca, exponiendo la anterior mezcla al sol ( 8 a 12 h) hasta alcanzar una humedad máxima del 13 al $14 \%$; molida constituye un concentrado con un contenido nutricional de PC 14,9\%, MS 87,73\%, FDN 55,2 \%, FDA 38,6 \%, ED 2,54 Mcal kg-1 MS, Ca 0,35 \% y P 0,25 \% (Torres, 2011).

En un experimento se evaluó la calidad y conservación de la sacharina elaborada a partir de caña integral (tallos, hojas y cogollo), miel final $(0,5$ y $10 \%)$ y pulidura de arroz $(0,10$ y $15 \%)$, se encontró que con el $5 \%$ de miel final y $15 \%$ de pulidura de arroz, se lograron los valores nutricionales más altos y la conservación del alimento alcanzó los setenta días, sin perder su valor nutritivo (Monroy et al., 2006).

La caña puede ofrecerse picada, cuyo consumo va a depender de la variedad y la edad de corte, la dureza que pueda tener y el tiempo de retención en el rumen (Moreno, 2007). El tamaño de las partículas del alimento es determinante de la dinámica ruminal. $\mathrm{Al}$ respecto, la incidencia de tres niveles de picado (trozos, molido grueso y fino) y dos de suplementación al 0,5 y $1 \%$ del peso vivo de caña de azúcar en base seca, se evaluaron en el consumo y ganancia de peso de terneros, generando un incremento en el consumo de caña fresca y en la ganancia de peso a mayor nivel de picado, pero este no fue significativo. Lo que sí afectó significativamente a estas variables fue el nivel de suplementación, obteniéndose un mayor índice de consumo de MS $(2,66)$ con el nivel de $1 \%$ de caña con molido fino (Benvenutti et al., 2006). También se puede suministrar molida o ripiada, ocasionando que la velocidad de paso a lo largo del tracto gastrointestinal sea tan alta, que se reduzca el aprovechamiento por parte del animal y no mejora las ganancias de peso. La alternativa sería suministrarla como suplemento en dietas muy secas que utilizan bloques, o de lo contrario usarla en poca cantidad (Moreno, 2007).

Debido a los bajos precios de la panela o azúcar, en algunas regiones se ha optado por diversificar la comercialización de la caña, mediante la producción de ensilaje para la alimentación animal a edades tempranas de corte. El ensilaje de caña, también ha sido estudiado en rumiantes, al comparar el ensilaje de caña de azúcar y ensilaje de maíz en una proporción de concentrado 70:30 en hembras Holstein-Friesian desde el destete hasta los 
470 días de edad. Los animales alimentados con ensilaje de caña mejoraron la condición corporal y conversión alimenticia, en comparación con los alimentados con ensilaje de maíz; sin embargo, no se encontraron diferencias en cuanto a las ganancias diarias de peso (Reyes et al., 2014).

Si bien la caña presenta altos rendimientos por unidad de área y sus deficiencias nutricionales pueden ser compensadas con la inclusión de aditivos, al momento de ensilar presenta iguales deficiencias y pérdidas de hasta $30 \%$ de la MS durante el almacenamiento. Al complementar el ensilaje de caña integral molida con $40 \%$ de porcinaza fresca sometida a fermentación, mejoró los indicadores de calidad, en niveles del 33,2 \% de materia seca, $7,45 \%$ de proteína total, $2,63 \%$ de grasa total y $8,44 \%$ de cenizas totales, frente a otros porcentajes de inclusión del 20 y $30 \%$ de porcinaza (Estrada et al., 2013).

Cuando se evaluó el ensilaje de caña con $40 \%$ de porcinaza fresca enriquecida con el aditivo microbiano VITAFERT previamente fermentado en vacas F1 (Cebú x Holstein), los valores de digestibilidad in situ e in vitro fueron superiores al $70 \%$, sin alteraciones en el estado sanitario de los animales. Al comparar en vacas alimentadas con ensilaje de maíz, no mostraron diferencias en producción de leche y consumo de ensilaje, pero sí produjeron menos metano ruminal (6,9 ppm), confiriéndole un efecto modulador a este tipo de ensilaje (Estrada et al., 2015).

Se han evaluado la urea, el hidróxido de sodio $(\mathrm{NaOH})$ y el maíz a nivel de laboratorio en microsilos para determinar el efecto sobre la MS, estracto etéreo (EE), CEN, PC y la estabilidad aeróbica del ensilaje de caña. En este sentido, las pérdidas de materia seca son mayores en los ensilajes sin aditivos químicos, debido al tipo de fermentación, donde la utilización de alcohol por las bacterias heterofermentativas genera producción de calor, por la actividad microbiana y pérdidas del mismo, por conducción, radiación, convección y evaporación. Estas variables se relacionan directamente con la oxidación de la MS, lo que ocasiona pérdidas en forma de dióxido de carbono (Hill y Leaver, 2002). Con respecto al EE, se ha evidenciado que la adición de urea al $1 \%$ incrementa esta fracción. Las CEN se incrementaron en aquellos casos en los que se adicionó urea y $\mathrm{NaOH}$ al $1 \%$; de igual manera, la PC también se incrementó con la mezcla de maíz (4\%), urea o $\mathrm{NaOH}(1 \%)$ y fue moderadamente superior en la mezcla con urea (más del $6 \%$ ). Esto sugiere una mejora en la estabilidad aerobia con el empleo de aditivos, siendo mayor el período de tiempo desde la apertura hasta la aparición de hongos en aquellos a los cuales se ha adicionado urea (Santos et al., 2014).

El ensilaje de caña presenta otras limitaciones, como el tipo de fermentación en la que se metaboliza el azúcar a alcohol o la presencia de levaduras como contaminantes naturales (Pedroso et al., 2008). Se han evaluado diferentes aditivos con el propósito de modificar la ruta fermentativa principal. Los productos de la fermentación, las pérdidas gaseosas y efluentes de los ensilajes de la caña de azúcar, han sido determinados con adiciones de $\mathrm{CaO}$ al 0, 0,8, 1,6 y $2,4 \%$, en asociación con un aditivo microbiano (Actobacillus buchneri), inoculado a niveles de 0, 50 000, 100 000 y 150000 unidades formadoras de colonias (UFC) por gramo de caña de azúcar. El nivel de 1,6\% de CaO, asociado al nivel de $50000 \mathrm{UFC} \mathrm{g}^{-1}$ de Lactobacillus buchneri, proporciona niveles adecuados de ácido láctico superiores al 4,5\% y de ácido acético (1\%), contenido moderado de ácido propiónico $(0,55 \%)$ y bajo de ácido butírico $(0,05 \%)$, permitiendo controlar la producción de etanol, las pérdidas gaseosas y efluentes, siendo esta una buena alternativa para mejorar la calidad del ensilaje de caña de azúcar. La inoculación del ensilaje con la bacteria Lactobacillus buchneri, reduce la concentración del etanol y disminuye la pérdida de la MS y por ende, de los demás nutrientes (Pádua et al., 2014). Dosis de $\mathrm{CaO}$ al $1 \%$ mejoró la digestibilidad de la MS del ensilaje de caña, redujo los componentes de la pared celular, mantuvo los niveles de FDN y hemicelulosa después de abierto el silo, promoviendo una mayor estabilidad de la composición química y calidad del ensilaje. Por otro lado, se aumentaron las poblaciones de bacterias ácido-lácticas y se disminuyó la producción de levaduras, niveles de $5 \mathrm{~g} \mathrm{~kg}^{-1} \mathrm{de} \mathrm{CaO}$

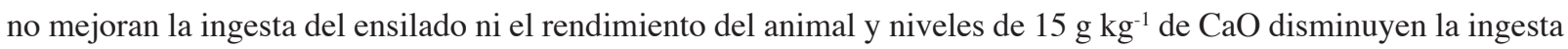
del ensilaje y el crecimiento del ganado (Balieiro et al., 2007; Cavali et al., 2010; Chizzotti et al. 2015). 


\section{Subproductos de la caña de azúcar en alimentación de rumiantes}

La cantidad y el volumen considerable de subproductos que se pueden aprovechar de la caña de azúcar son potencialmente altos, dado que por cada tonelada de panela se obtiene una tonelada de subproductos. Estos se convierten en materia prima para la suplementación animal, en diferentes formas de uso y variaciones en la adición de otras sustancias que pueden mejorar la disponibilidad de los nutrientes y, por ende, su digestibilidad, o como materia prima para la elaboración de otras alternativas de alimentación como harinas y bloques (Hernández, 2002), las cuales han sido debidamente documentadas y probadas en diferentes especies de animales, especialmente rumiantes (Hidalgo et al., 2009; Berman, 2011).

El cultivo de la caña de azúcar genera residuos agrícolas como el cogollo y hojas verdes ( $8 \%)$, vainas y hojas secas $(20 \%)$, y subproductos industriales derivados de la manufactura, no solo de la panela sino también del azúcar tales como: el bagazo, el bagacillo, la cachaza, el melote, la melaza y la vinaza. Estos presentan diferentes características en cuanto a su composición química, como un alto contenido de fracciones de pared celular, alta concentración de sacarosa y otros azúcares solubles, bajos contenidos de proteína y minerales (Cuadro 2), los cuales se han empleado en la elaboración de diferentes dietas para la alimentación de rumiantes, previo un tratamiento de tipo físico, químico o biológico (Martín, 2004).

El cogollo de la caña, constituido por hojas y una sección de tallo no es utilizado en la producción de panela (Pachón el al., 2005). En un estudio morfológico y bromatológico de las variedades 02-CP72-2086, 03CO-997, 24MEX68-1366 y 202MEX55-32 producidas en la región de la Huasteca Potosina (México), la proporción de las puntas o cogollo correspondieron del 18,9 al $24,5 \%$ de la caña, la cual no se vio modificada por la variedad. De igual manera, las medias generales de MS, PC, CEN, FDN y FDA, no se vieron afectadas por la variedad ni el tipo de cosecha (verde o quemada). Para mejorar el aprovechamiento de los cogollos es recomendable cosecharlos antes de realizar la quema y así, disponer de mayores volúmenes de biomasa (Ramírez et al., 2014).

La producción de cogollo puede ser del 15 al $25 \%$ de la producción de tallos molibles de acuerdo con el estado de madurez de la caña y las condiciones ambientales (García et al., 2007). El cogollo es una buena fuente de forraje, debido a su contenido de FDN (Cuadro 2), aunque su contenido de PC es bajo, por lo que es necesario suplementarlo con proteína verdadera o compuestos nitrogenados no proteicos.

Con el fin de mejorar la disponibilidad de los nutrientes del cogollo, Orta (2016) utilizó un tratamiento físico y químico a través de la molienda y aplicación de $\mathrm{NaOH}$ al 11,5\% en un tiempo de retención de 10 min, deteniendo la reacción con una solución de melaza-urea al 71,4 y 9,5\%. Encontró una variación porcentual positiva en el contenido de la CEN y PC del 73 y $164 \%$, en su orden, y una variación porcentual negativa en la FC y EE del 14,8 y $14,1 \%$. El contenido de humedad también incrementó de tal forma que el tiempo de almacenamiento fue limitado (113 días).

En algunas regiones de Colombia donde la producción de caña se lleva a cabo en condiciones de ladera, el cogollo es usado para la alimentación de los animales de carga (caballos y mulas). Se les suministra durante el día y la noche, aunque no todo el cogollo que se produce en los cultivos de caña es consumido por estos animales. Se puede estimar que alrededor de la mitad del cogollo se descompone en la superficie del suelo junto con la hojarasca. No obstante, existen estudios relacionados con la utilización del cogollo en la alimentación animal, en donde se compararon vacas Holstein alimentadas dos veces al día con cogollo al cual, después de picarlo, lo trataron con una solución deslignificante, luego de un período de reposo de $24 \mathrm{~h}$ le agregaron un compuesto de quelatos, ácidos orgánicos, bionutrientes, $100 \mathrm{~g}$ de urea, $2 \mathrm{~kg}$ de melaza vaca ${ }^{-1}$ día $^{-1}$, concentrado, maíz, orujo y maracuyá versus vacas que recibieron concentrado y maíz sin cogollo tratado. La producción promedio diaria de leche por vaca fue de 18,2 a 25 l, en su orden, con una disminución porcentual de los costos del alimento vaca día ${ }^{-1}$ del 59,83\% (Timana et al., 2017). 
Cuadro 2. Composición química y mineral de los subproductos de la agroindustria de la caña de azúcar. Laboratorio de Nutrición Animal de la Corporación Colombiana de Investigación Agropecuaria (AGROSAVIA), Tibaitatá, Colombia. 2017.

Table 2. Chemical and mineral composition of the by-products of the sugarcane agro-industry. Animal Nutrition Laboratory of the Corporación Colombiana de Investigación Agropecuaria (AGROSAVIA), Tibaitatá, Colombia. 2017.

\begin{tabular}{|c|c|c|c|c|}
\hline Componente & Cogollo & Bagazo & Cachaza & Melote \\
\hline MS (\%) & 25,0 & 44,6 & 25,5 & 44,8 \\
\hline $\mathrm{H}(\%)$ & 75,0 & 55,4 & 74,5 & 55,2 \\
\hline $\operatorname{CEN}(\%)$ & 6,4 & 2,3 & 3,4 & 10,7 \\
\hline MO (\%) & 93,6 & 97,7 & 96,6 & 89,4 \\
\hline $\mathrm{PC}(\%)$ & 4,9 & 2,2 & 9,9 & 11,1 \\
\hline $\mathrm{EE}(\%)$ & 0,7 & 0,4 & 7,6 & 4,9 \\
\hline $\mathrm{FC}(\%)$ & 28,3 & 33,3 & 0,5 & 0,2 \\
\hline FDN $(\%)$ & 68,2 & 71,8 & - & - \\
\hline $\mathrm{FDA}(\%)$ & 44,5 & 40,7 & - & - \\
\hline HEMICEL (\%) & 23,7 & 31,1 & - & - \\
\hline $\operatorname{CEL}(\%)$ & 40,3 & 34,1 & - & - \\
\hline $\operatorname{LIG}(\%)$ & 4,2 & 6,6 & - & - \\
\hline $\mathrm{N}(\%)$ & 0,7 & 0,5 & 1,8 & 1,1 \\
\hline $\mathrm{P}(\%)$ & 0,2 & 0,1 & 0,2 & 0,1 \\
\hline $\mathrm{K}(\%)$ & 2,1 & 1,9 & 1,8 & 0,5 \\
\hline $\mathrm{Ca}(\%)$ & 0,3 & 0,1 & 0,2 & 0,1 \\
\hline $\operatorname{Mg}(\%)$ & 0,2 & 0,1 & 0,1 & 0,1 \\
\hline $\mathrm{S}(\%)$ & 0,2 & 0,1 & 0,2 & 0,1 \\
\hline $\mathrm{Fe}(\mathrm{mg} / \mathrm{kg})$ & 78,2 & 1241,3 & 1330,0 & 1078,9 \\
\hline $\mathrm{Cu}(\mathrm{mg} / \mathrm{kg})$ & $<3$ & 4,1 & 28,6 & 32,4 \\
\hline $\mathrm{Mn}(\mathrm{mg} / \mathrm{kg})$ & 34,1 & 36,1 & 45,2 & 45,1 \\
\hline $\mathrm{Zn}(\mathrm{mg} / \mathrm{kg})$ & 26,0 & 11,0 & 93,5 & 59,0 \\
\hline B (mg/kg) & 1,6 & 1,9 & 2,1 & 4,5 \\
\hline $\mathrm{C}(\mathrm{mg} / \mathrm{kg})$ & 45,6 & 47,8 & 56,7 & 58,3 \\
\hline
\end{tabular}

MO: materia orgánica; HEMICEL: hemicelulosa; CEL: celulosa; LIG: lignina; N: nitógeno; P: fósforo; K: potasio; Ca: calcio; Mg: magnesio; S: azufre; Fe: hierro; Cu: cobre; Mn: manganeso; Zn: zinc; B: boro; C: carbono / MO: organic matter; HEMICEL: hemicellulose; CEL: cellulose; LIG: lignin N: nitrogen; P: phosphorus; K: potassium; Ca: calcium; Mg: magnesium; S: sulfur; Fe: iron; $\mathrm{Cu}$ : copper; $\mathrm{Mn}$ : manganese; $\mathrm{Zn}$ : zinc; B: boron; C: carbon.

También se han realizado evaluaciones con el ensilaje de cogollo de la caña fresca en la alimentación de novillos de levante. Los animales alimentados únicamente con ensilaje de cogollo perdieron $232 \mathrm{~g}_{\text {animal }}{ }^{-1}$ día $^{-1}$, mientras que los suplementos con porciones de nitrógeno no proteico (NNP) tuvieron aumentos significativos de peso de $362 \mathrm{~g}$ animal $^{-1}$ día $^{-1}$. El cogollo no es ampliamente utilizado, debido a que su uso se limita por el transporte y almacenamiento, al ser este un residuo muy voluminoso (Orta, 2016).

Otro importante subproducto que se obtiene después de extraer el jugo de la caña es el bagazo, el cual tiene muchos usos comerciales, como medio de cultivo para insectos, levaduras y hongos, como sustrato para la 
fabricación de enzimas industriales, pulpa de papel, alcohol y otros productos químicos (Barker et al., 2000). Este tiene algún valor para la alimentación de los rumiantes (Reddy et al, 2002; Cabello et al., 2008; Loh et al., 2013), conserva el $50 \%$ de los azúcares, lo cual es una ventaja desde el punto de vista nutricional, pero al mismo tiempo una pérdida para el productor de la panela (Llanes, 2012).

El incluir al bagazo como única fuente de fibra o como suplemento de diferentes raciones, ha mostrado resultados satisfactorios. Se considera uno de los subproductos más importantes que se generan en el proceso agroindustrial de la producción de azúcar de caña, tanto por su composición fibrosa como por su valor energético; además, ha sido utilizado como fuente de energía a través de la combustión, y como materia prima para muchos co-productos de alto valor agregado como la pulpa química papelera (Llanes, 2012).

El bagazo de muy alto contenido de fibra presenta una baja digestibilidad, alrededor del $25 \%$, el cual para ser utilizado requiere tratamientos físico-químicos que ayuden a mejorarlo, ya que incorporándolo en la dieta directamente solo haría un efecto físico de llenado, con el agravante que el animal tendría que gastar más energía en digerirlo. Su inclusión en las dietas no debería pasar del $10 \%$ (Martin, 2009).

Desde el punto de vista de su empleo en la alimentación animal, son muchos los estudios desarrollados en torno a este subproducto desde hace varias décadas, en los cuales se ha ido incorporando diferentes metodologías y procedimientos para mejorar su aplicabilidad en la alimentación animal. Un ejemplo de ello, es el bagazo fermentado elaborado a partir de su tratamiento con un álcali y la incorporación de bacterias ácido lácticas. En Veracruz (México), se desarrolló un alimento pre-digerido a partir del bagazo para ganado bovino, con una granulometría tipo harina, acompañado de una adecuada suplementación proteica. El incremento de la digestibilidad de este componente fibroso se llevó a cabo mediante un tratamiento químico con una base para detener la reacción alcalina y enriquecer proteicamente, además se le adicionó miel más urea al $2 \%$. A su vez, en calidad de suplemento proteico, se utilizaron cereales como insumos energéticos y arbustos forrajeros, los cuales se analizaron mediante pruebas de digestibilidad in vitro, corroborando la mayor digestibilidad de este subproducto y su aplicabilidad en la alimentación de bovinos (Llanes, 2012).

Al evaluar la suplementación de bovinos en fase de ceba con bagazo de caña enriquecido con el hongo Pleurotus ostreatus, no se encontraron diferencias significativas, sin embargo, los animales suplementados obtuvieron mayores ganancias y la relación beneficio-costo fue superior frente a los que no recibieron suplementación (Castaño et al., 2012).

Otro subproducto resultante de la industrialización de la caña es la cachaza, la cual se obtiene de la limpieza del jugo por medio de la utilización de plantas como el balso blanco (Helicarpus americanus). Físicamente, la cachaza es un material esponjoso, amorfo, de color oscuro a negro, que absorbe grandes cantidades de agua, rico en fósforo, calcio y nitrógeno y pobre en potasio (Pachón et al., 2005). Su contenido de humedad es alto, alrededor de 80 a 88 $\%$, lo cual puede provocar procesos fermentativos, por lo tanto, el secado es fundamental para que esta pueda ser almacenada y utilizada en la alimentación animal.

En la región de la Huasteca (México), productora de ganado en pastoreo y con ingenios azucareros que facilitan y disminuyen los costos por manipulación y transporte, se llevaron a cabo treinta formulaciones de bloques multinutricionales con diferentes porcentajes de inclusión de cachaza, los cuales se evaluaron en ganado Beefmaster, donde la formulación más aceptada fue aquella que contenía un $15 \%$ del total, debido a que el análisis de palatabilidad y consumo diario fueron los ideales (Hernández, 2011).

Adicionalmente, por deshidratación de la cachaza se produce el melote, condición que facilita su conservación por períodos superiores a un mes. Sin embargo, el melote obtenido equivale a la mitad del peso original de la cachaza; este producto es deficiente en proteína cruda (Cuadro 2), por lo que ha dado buenos resultados al mezclarlo con nitrógeno no proteico. Pachón et al. (2005), en el municipio de Utica (Cundinamarca), probaron en bovinos, bloques multinutricionales con un contenido del $50 \%$ de melote y $5 \%$ de urea, entre otras materias primas, obteniendo ganancias diarias de peso de $0,848 \mathrm{~kg}_{\text {animal }}{ }^{-1}$ día ${ }^{-1}$ cuando se comparó con el testigo, el cual 
produjo ganancias de $0,769 \mathrm{~kg}_{\text {animal }}{ }^{-1} \mathrm{día}^{-1}$. Los aportes de este tipo de investigaciones son importantes, ya que se constituyen en una opción para mantener a los animales en época de escasez, además, evita la venta de animales a bajos precios por la falta de alimento para los mismos.

Un subproducto de gran utilidad en la alimentación animal como fuente de energía y aglutinante en la elaboración de bloques multinutricionales, son las mieles, más comúnmente conocidas como melaza, la cual es un líquido denso y viscoso de color oscuro producto de la refinación de la sacarosa procedente de la caña de azúcar (Berman, 2011). Es importante aclarar que existen diferentes melazas, desde la que contiene todo el azúcar (rica), hasta la que resulta de completar el proceso de extracción en el ingenio (final). Esto permite que exista una gran diferencia en la composición química de estas, con un contenido de nitrógeno del 0,44 \% para la final y 0,26\% para la rica. Sin embargo, el contenido de azúcares totales es menor en la final $(58,3 \%)$ con respecto a la rica $(86,10 \%)$, y es esta la que se utiliza en el ganado vacuno. Reviste gran interés para el fabricante extraer la mayor cantidad de azúcar posible de la miel rica (Martín, 2004).

Al profundizar aún más en la revisión de literatura se pueden rescatar los diferentes usos que se da a la melaza en la alimentación del ganado vacuno, como una fuente de azúcares y mejoramiento de la palatabilidad hasta su utilización como principal ingrediente en raciones para rumiantes. Se destaca la relevancia de incorporarla tanto con nitrógeno no proteico como con proteína verdadera. Su importancia radica en la utilización en la producción tanto de leche como de carne. También se destaca su empleo como suplemento en forma líquida con la adición de nitrógeno no proteico para la suplementación de bovinos de ceba. Este subproducto es uno de los más relevantes en los países donde se produce la caña, ya que a partir de este es posible desarrollar diferentes estrategias de alimentación que permitan optimizar los sistemas productivos, especialmente en el trópico (Vélez et al., 2014; Suarez et al., 2016).

Es importante dar a conocer que los subproductos no solo provienen de la transformación de materia prima en alimentos, sino también de la destilería. Es el caso de la vinaza, la cual a inicios de 1996 era considerada como un residuo de la destilación de la melaza con origen en la caña de azúcar, con un $92 \%$ de agua, lo que imposibilitaba su utilización en la industria y el agro. Por lo tanto, fue necesario concentrarla hasta el porcentaje máximo exigido por la tecnología a través de las destilerías, las cuales logran reducir su volumen y facilitar su traslado para algunos usos, fundamentalmente en la alimentación de bovinos (Irisarri, 2006).

Como se puede apreciar, a pesar de la diversidad de subproductos que se derivan del cultivo de la caña y que pueden ser utilizados en la alimentación animal, con la consecuente reducción de costos de producción, es necesario el desarrollo o aplicación de prácticas químicas, físicas y biológicas, que mejoren la digestibilidad de estos materiales, debido a que son altamente fibrosos y con bajo contenido de nutrientes, que conllevan a la utilización del uso de NNP bajo la forma de urea, que resulta en una manera eficaz de enriquecer forrajes de bajo contenido proteico en condiciones del trópico.

\section{Implicaciones medioambientales}

Otro punto a favor que engloba todo lo relacionado con los subproductos, es el riesgo que presenta al medio ambiente, ya que muchos de estos son considerados fuentes de contaminación. Es el caso de las aguas residuales que llevan consigo una cantidad de compuestos tanto orgánicos como inorgánicos, que pueden ser contaminantes de las fuentes de agua si no reciben un tratamiento adecuado. Los mostos o vinazas de residuos alcohólicos, son productos viscosos con 4 a $10{ }^{\circ} \mathrm{Brix}$, que a temperaturas y concentraciones altas son muy corrosivos. La cachaza o torta de filtro, físicamente es el principal residuo de la industria del azúcar de caña, con una producción entre 30 y $50 \mathrm{~kg} \mathrm{t}^{-1}$ de materia prima procesada, lo cual representa entre 3 y $5 \%$ de la caña molida (García et al., 2011). Este porcentaje y su composición varían con las características agroecológicas de la zona, con el cultivo cosechado, eficiencia de fábrica y método de clarificación empleado, entre otros factores. Se produce durante la clarificación 
que se hace al jugo de caña y se recoge a la salida de los filtros al vacío, presentando aproximadamente un $25 \%$ de materia seca.

Este material contiene muchos de los coloides de la materia orgánica, originalmente dispersados en el jugo, conjuntamente con aniones orgánicos e inorgánicos que precipitan durante la clarificación. Otros compuestos no azucarados son incluidos en esos precipitados, tales como suelo, cera, sustancias albuminoides, calcio, fósforo y nitrógeno (Zérega, 1993).

Otro residuo del proceso de transformación de la caña es la producción de dextrana. Las dextranas son polisacáridos de elevado peso molecular y baja solubilidad; son compuestos indeseables, su contenido en la propia caña es muy bajo, pero se forman por acción de la enzima dextranasacarasa de microorganismos contaminantes que se alojan en la savia de la planta o la atacan posteriormente al ser dañada su corteza (Rodríguez, 2005). Con el fin de ocupar menos espacio, el bagazo se comprime para formar pacas que se apilan en el exterior del ingenio, normalmente se deja espacio entre las pilas para que el aire circule y las pacas se sequen; posteriormente, se envían a otras industrias para utilizarlas de inmediato o almacenarlas hasta su uso en espacios abiertos. El bagazo fresco y húmedo apilado a la intemperie produce un residuo de jugo que es susceptible de ser fermentado por levaduras. La temperatura favorece el crecimiento de muchas especies de hongos, principalmente actinomicetos termo y mesofílicos. Cuando el bagazo está viejo y seco se enmohece y puede contener grandes cantidades de esporas (240 a 500 millones por gramo) de las que una parte se liberan hacia el ambiente, sobre todo cuando se manejan y transportan las pacas, o cuando se rompen, se trituran o se muelen. En México, los trabajadores que se enferman de bagazosis son aproximadamente el $50 \%$ de los expuestos (Svartz et al., 2005).

Se ha demostrado el uso potencial en la alimentación animal y el manejo adecuado que se pueden dar a los residuos de la cosecha de caña. Por lo tanto, es necesario validar a través de la investigación, el uso racional de los residuos de postcosecha en alimentación animal, con el fin de agregar valor al cultivo de caña de azúcar. Todo esto en pro de mejorar y diversificar la economía de los productores, concientizarlos en el manejo racional de los residuos derivados de este tipo de producción.

\section{Conclusiones}

El cultivo de caña además de planta productora de azúcares y mieles, puede producir muchos derivados, los cuales tienen diferente aplicabilidad desde la ciencia y tecnología de alimentos, el sector de energías renovables, el área de productividad agrícola regional, el sector pecuario a nivel de ganadería y otras especies. Es una planta que participa en la captura de manera eficiente de los niveles de $\mathrm{CO}_{2}$, factor que repercute en la regulación de los gases de efecto invernadero.

Desde el punto de vista pecuario, los estudios demuestran que existe un gran potencial de uso de los subproductos de caña para generar opciones para la nutrición animal, a través del uso de diversas tecnologías y recomendaciones de uso. No obstante, uno de los factores que requieren mayor profundidad de investigación es la degradabilidad de la materia seca contenida en los subproductos de la caña, a través de diferentes procesos físicos, químicos y biológicos, que sean de fácil adopción por el pequeño productor.

La adopción de diversas estrategias de valorización de subproductos con fines de alimentación animal, se ve limitada por varios factores: en primer lugar por la disponibilidad de los mismos en algunas regiones en donde su uso, especialmente del bagazo, se destina primordialmente a la combustión en las hornillas; en segundo lugar, el desconocimiento por parte de ganaderos, trapicheros y cañicultores, de las tecnologías apropiadas para el contexto local, que resulten rentables, debido a que su uso requiere mano de obra adicional para transporte, desde los lotes o trapiches hasta el lugar de transformación. 
Es importante determinar la cantidad de residuos y subproductos resultantes de la agroindustria de la caña de azúcar en un área determinada, la cual estará en función de las características de planta, del manejo y de las condiciones edafoclimáticas, de tal manera, que sea posible planificar y decidir sobre la utilización de los mismos con el fin de solventar las implicaciones medioambientales que genera la producción de azúcar o panela, del cual hay diversidad de aplicaciones con abundantes perspectivas comerciales.

\section{Agradecimientos}

A la Corporación Colombiana de Investigación Agropecuaria (AGROSAVIA) y al Sistema General de Regalías, por la financiación del estudio que dio como base esta revisión.

\section{Literatura citada}

Aguilar, N. 2014. Reconversión de la cadena agroindustrial de la caña de azúcar en Veracruz-México. Nova Sci. 6(12):125-161. doi:10.21640/ns.v6i12.37

Aguirre, J., R. Magaña, S.R., Martínez, A. Gómez, J.C. Ramírez, R. Barajas, y D.E. García. 2010. Caracterización nutricional y uso de la caña de azúcar y residuos transformados en dietas para ovinos. Zootec.Trop. 28:489-497.

Albarracín, L.C., L. Sánchez, y G. García. 2004. Caña de azúcar ensilada: Una alternativa de alimentación para ganado bovino en confinaiento. AGROSAVIA, COL. https://repository.agrosavia.co/bitstream/handle/20.500.12324/15268/42699_46796. pdf?sequence=1\&isAllowed=y (consultado 10 mar. 2019).

Aranda, E.M., P. Ruiz, G.D. Mendoza, C.F. Marcoff, J.A. Ramos, y A. Elías. 2004. Cambios en la digestión de tres variedades de caña de azúcar y sus fracciones de fibra. Rev. Cub. Cienc. Agric. 38:137-144.

Ávila, D.N., A.R. Bobadilla, F.A. Castrejón, y L.G. Melgarejo. 2017. Prácticas de producción y aprovechamiento de forrajes. UNAM, MEX. http://papimes.fmvz.unam.mx/proyectos/manuales_nutricion/Aprovechamiento_Forrajes.pdf (consultado 24 mar. 2019).

Balieiro, G., G. Siqueira, R. Reis, J. Nogueira, M. Roth, e A.P. Roth. 2007. Óxido de cálcio como aditivo na ensilagem de canade-açúcar. R. Bras. Zootec. 36:1231-1239. doi:10.1590/s1516-35982007000600003

Barker, A.V., T.A. O’brien, and M.L. Stratton. 2000. Description of food processing by-products. In: J.F. Power, and W.A. Dick, editors, Land apolication of agricultural, industrial, and municipal by-products. SSSA Book Series 6. Soil Science Society of America, Madison, WI, USA. p. 63-106. doi:10.2136/sssabookser6.c2

Bastidas, L., R. Ramón, O. De Sousa, A. Valle, y V. Jesús. 2010. Calidad forrajera de cinco variedades de azúcar en Santa Cruz de Bucaral, Estado Falcón, Venezuela. Rev. Estud. Transdiscip. 2(2):63-75.

Benvenutti, M.A., D.R. Pavetti, y F.C. Moreno. 2006. Efecto del tamaño de partícula de caña de azúcar y nivel de suplementación sobre el consumo y ganancia de peso de novillos en confinamiento invernal. Rev. Arg. Prod. Anim. 26:63-69.

Berman, J. 2011. Desarrollo de alimento animal melazado, y enriquecido a partir de insumos no-convencionales y subproductos de la caña de azúcar para engorda de ganado bovino en la etapa de finalización. Instituto Politécnico Nacional, MEX. https://tesis.ipn.mx/handle/123456789/11785 (consultado 18 abr. 2018).

Bolufer, P. 2010. La fotosíntesis C4 de alto rendimiento. Interpresas net, ESP. http://www.interempresas.net/Agricola/ Articulos/44231-La-fotosintesis-C4-de-alto-rendimento.html (consultado 11 feb. 2018). 
Cabello, A., A. Torres, and O. Almazán. 2008. The economical viability of animal production base on sugarcane co-products under the presente prices commodities. Sugar Tech 10: 25-28. doi:10.1007/s12355-008-0004-2

Cavali, J., O. Gomes, S. Valadares, E.M. Santos, G.G. Pinto, M.V. Santos, M. Oliveira, and J.F. Huback. 2010. Bromatological and microbiological characteristics of sugarcane silages treated with calcium oxide. R. Bras. Zootec. 39:1398-1408. doi: $10.1590 /$ S1516-35982010000700002

Castaño, N., P. Goyes, L.C. Albarracin, y F.J. López. 2012. Uso del bagazo enriquecido con el hongo Pleurotus ostreatus, en dietas para bovinos estabulados en ceba. Biotecnol. Sector Agropecu. Agroind. 10(2):25-33.

CENGICAÑA (Centro Guatemalteco de Investigación y Capacitación de la caña en Guatemala). 2014. El cultivo de la caña de azúcar en Guatemala. CENGICAÑA, GTM. https://cengicana.org/files/20170103101309141.pdf (consultado 23 dic. 2017).

Chavez, M. 2008. Uso de la caña de azúcar como forraje. Ventana Lechera 10(3):45-51.

Chizzotti, F.H.M., O.G. Pereira, S.C. Valadares, M.L. Chizzotti, R.T.S. Rodrigues, L.O. Tedeschi, and T.C. Silva. 2015. Does sugar cane ensiled with calcium oxide affect intake, digestibility, performance, and microbial efficiency in beef cattle? Anim. Feed Sci. Techol. 203:23-32. doi:10.1016/j.anifeedsci.2014.12.014

CONADESUCA (Comité Nacional para el Desarrollo sustentable de la Caña de Azúcar). 2015. Ficha técnica del cultivo de la caña de azúcar (Saccharum officinarum L.). Gobierno de México, MEX. https://www.gob.mx/cms/uploads/attachment/ file/141823/Ficha_T_cnica_Ca_a_de_Az_car.pdf (consultado 25 sep. 2018).

Cordeiro, J.D., G.D. Gonçalves, J.M. de-Souza, M. Wagner, A. Pereira, and J.R. Silva. 2017. Biometric and chemical characteristics of sugarcane varieties for use as forage in limiting soil water conditions. R. Bras. Zootec. 56:384-392. doi:10.1590/s 1806-92902017000500003

Estrada, J., E. Aranda, G. Pichard, y F.J. Henao. 2013. Ensilaje de caña de azúcar integral enriqucido con porcinaza fresca. Orinoquia 17(1):38-49. doi:10.22579/20112629.47

Estrada, J., N. Villa, y F.J. Henao. 2015. Digestibilidad de un ensilaje de caña de azúcar con porcinaza, y su evaluación en un sistema bovino de doble propósito. Pastos y Forrajes 38(4):25-430.

FAOSTAT. 2016. Producción / rendimiento de azúcar, caña en Mundo. FAO, Roma, ITA. http://www.fao.org/faostat/es/\#data/ QC/visualize (consultado 23 dic. 2017).

FEDEPANELA (Federación Nacional de Productores de Panela). 2012. Aprovechamiento de subproductos de la caña panelera en la alimentación animal. FEDEPANELA, Bogotá, COL.

Fernández, Y., R. Pedraza, Y. Baños, A. Llanes, I. Torres, J. Montalvan, y A. Noy. 2016a. Indicadores de crecimiento de una población de 48 clones de caña de azúcar (Saccahrum spp.) con valor forrajero. Agrisost 22(3):17-28.

Fernández, Y., R. Pedraza, A. Llanes, Y. Baños, I. Torres, J. Montalván, y Y. Ortega. 2018. Indicadores de la composición química en caña de azúcar según edad de rebrote, cultivar y fracción de la planta. Rev. Prod. Anim. 30(1):1-7.

Fernández, Y., R.M. Pedraza, A. Llanes, J.A. Sánchez, M. León, C.E. González, M.L. Torrez, M. León, C.E. González, M.L. Álvarez, I. Torres, J. Montalván, y A. Noy. 2016b. Digestibilidad in vitro de rebrote del forraje integral de dos nuevos cultivares de caña de azúcar (Saccharum spp. C97-366 y C99-374). Rev. Prod. Anim. 28(1):27-33.

Fundora, O., P.C. Martín, A. Vera, y J.L. Hernández. 2007. Comportamiento productivo, conducta alimentaria y composición de las canales de machos cebú en la etapa de ceba, alimentados con caña de azúcar y concentrados mezclados o no. Rev. Cub. Cienc. Agríc. 41:30-34.

Galindo, R.R., y W.A. Rubio. 2011. Conservación de caña de azúcar picada usando hidroxido de calcio. Proyecto de graduación. Zamorano, HON. 
García, H., L. Albarracín, A. Toscano, N. Santana, y O. Insuasty. 2007. Guía tecnológica para el manejo integral del sistema productivo de caña panelera en la alimentación animal. CONECTARURAL, COL. http://conectarural.org/sitio/sites/ default/files/documentos/Guia_panelera.pdf (consultado 18 abr. 2018).

García, L., E. Vinent, Y. Sardiñas, and M.R. González. 2016. Protein foliage (kenaf and cassava) in rations of sugarcane without urea, for dairy cows. Pastos y Forrajes 39(3):138-142.

García, R., E. Rios, A. Martínez, F.R. Ramos, J.S. Cruz, y M.C. Cuevas. 2011. Uso de cachaza y bagazo de caña de azúcar en la remoción de hidrocarburos en suelo contaminado. Rev. Int. Contamin. Amb. 27(1):31-39.

Garriz, M., y A. López. 2002. Suplementación con nitrógeno no proteico en rumiantes. Sitio Argentino de Producción Animal, ARG. http://www.produccion-animal.com.ar/informacion_tecnica/suplementacion_proteica_y_con_nitrogeno_ no_proteico/07-suplementacion_con_nitrogeno.pdf (consultado 19 abr. 2018).

Gutierrez, D, Y. Gutierrez, P.A. González, A. Elías, R. García, R. Stuart, y L. Sarduy. 2014. Utilización de la caña de azúcar en mezclas integrales frescas para la alimentación de corderos. Rev. Centro Azúcar 41(3):64-77.

Guerra, S. 2009. ¿Qué debemos tener en cuenta para incorporar la caña de azúcar en la dieta de nuestros animales? Sitio Argentino de Producción Animal, ARG. http://www.produccion-animal.com.ar/produccion_y_manejo_pasturas/Cania_ azucar/22-dieta.pdf (consultado 10 mar. 2019).

Hernández, D. 2002. Utilización de la caña panelera y sus subproductos en la alimentación animal. FEDEPANELA, Bogotá, COL.

Hernández, R. 2011. Conversión de la cachaza azucarera en co-productos de valor agregado para la alimentación de ganado bovino en el marco de un desarrollo sustentable. Tesis MSc., Instituto Politécnico Nacional, Altamira, MEX.

Hidalgo, K., B. Rodríguz, M. Valdivié, y M. Febles. 2009. Utilización de vinaza de destilería como aditivo para pollos en ceba. Rev. Cub. Cienc. Agríc. 43:281-284.

Hill, J., and J.D. Leaver. 2002. Changes in chemical composition and nutritive value of urea treated whole crop wheat during exposure to air. Anim. Feed Sci. Technol. 102:181-195. doi:10.1016/S0377-8401(02)00258-4

Ishikawa, S., S. Ando, T. Sakaigaichi, Y. Terajima, M. Sugiura, and M. Matsuoka. 2007. Dry matter production and N accumulation in sugarcane for use as animal feed. Proc. Soc. Sugar Cane Technol. 26:289-297.

Irisarri, D. 2006. Usos industriales y agrícolas de la vinaza de caña de azúcar. Tecnicaña 10(17):19-24.

Irola, J., Y. García, y J. Hernández. 2016. Bovinos machos en pastoreo restringido complementados con caña de azúcar y maíz. AIA 20(1):43-48.

Juárez, F., J. Vilaboa, y P. Díaz. 2009. La caña de azúcar (Saccharum officinarum): una alternativa para la sustitución del maíz (Zea mays) en la alimentación de bovinos de engorda. Sitio Argentino de la producción Animal, ARG. http:// www.produccion-animal.com.ar/informacion_tecnica/invernada_o_engorde_a_corral_o_feedlot/69-cana_azucar.pdf (consultado 22 mar. 2019).

Kling, K.A., S.C. Valadares, H.B. Kling, M. I. Leão, R. F. Diniz, E. Detmann, e P.M. Nalon. 2008. Parâmetros nutricionais de novilhas de corte alimentadas com cana-deaçúcar tratada com óxido de cálcio e diferentes níveis de concentrado. R. Bras. Zootec. 37:1301-1310. doi:10.1590/S1516-35982008000700023

Llanes, D. 2012. Desarrollo técnico-económicamente viable de harinas forrajeras predigeridas y enriquecidas proteicamente a partir del bagazo de caña de azúcar. Tesis M.Sc., Instituto Politécnico Nacional, Altamira, MEX.

Loh, Y.R., D. Sujan, M.E. Rahman, and C.A. Das. 2013. Sugarcane bagasse - The future composite material: a literatura review. Res. Conserv. Recycling 75:14-22. doi:10.1016/j.resconrec.2013.03.002 
López, I., E. Aranda, J. Ramos, y G. Mendoza. 2003. Evaluación nutricional de ocho variedades de caña de azúcar con potencial forrajero. Rev. Cub. Cienc. Agríc. 37:381-386.

Martín, P.C. 2004. La melaza en la alimentación del ganado vacuno. AIA 8(3):3-19.

Martín, P.C. 2005. El uso de la caña de azúcar para la producción de carne y leche. Rev. Cub. Cienc. Anim. 39:427-438.

Martin, P.C. 2009. El uso de residuales agroindistriales en la alimentación animal en Cuba: pasado, presente y futuro. AIA13(3):3-10.

Martínez, A.L., y J.F. Sánchez. 2007. Efectos del nitrato en la alimentación de rumiantes. Engormix, Montreal, CAN. https:// www.engormix.com/ganaderia-carne/articulos/efectos-nitrato-alimentacion-rumiantes-t26899.htm (consultado 21 mar. 2019).

Mathier, D., P. Saleme, M. Bragachini, F. Sanchez, M. Bragachini, y J. Mendez. 2013. La caña de azúcar como cultivo energético. INTA, ARG. https://inta.gob.ar/documentos/la-cana-de-azucar-como-cultivo-energetico (consultado 24 set. 2018).

Menezes, A.M., C.A. Cruz, C.B. Tanure, V. Peripolli, M.B. Castro, H. Louvandini, and C. McManus. Evaluation of carcass and muscle traits in Santa Ines female lambs finished with different agricultural products. Arq. Bras. Med. Vet. Zootec. 68:1259-1266. doi:10.1590/1678-4162-8681

Mesén, M., y J.R. Durán. 2011. La caña de azúcar (Saccharum officinarum) y su uso en la ganadería. INTA, LAICA, y MAG, Sna José, CRI.

Monroy, J.M., E. Aranda, G, Mendoza, J.A. Ramos, J. Herrera, M. Cobos, y F. Izquierdo. 2006. Elaboración y conservación de Saccharina a partir de caña de azúcar integral, con la adición de melazay pulidura de arroz. Rev. Cub. Cienc. Agríc. 40(2):167-172.

Moreno, F.L. 2007. La caña panelera (Saccharum officinarum) en la alimentación del ganado. Panela Monitor. www. panelamonitor.org/documents/353/la-cana-panelera-saccharum-officinarum-en-la-alime/download/ (consultado 24 set. 2018).

Nogueira, F., M. Dal-Secco, D. Azevedo, D. de-Sousa, e J. Santos. 2012. Desempenho de novilhas de corte alimentadas com cana hidrolisada. Ciênc. Anim. Bras.13(1):8-14. doi:10.5216/cab.v13i1.8396

Nussio, L.G., P. Schmidt, e A.F. Pedroso. 2003. Silagem de cana-de- açúcar. Embrapa, BRA. https://www.alice.cnptia.embrapa. br/alice/bitstream/doc/46603/1/PROCI2003.00077.pdf (consultado 24 mar. 2019).

Orta, V. 2016. Cogollo de caña de azúcar pre-digerido y suplementado como alternativa alimenticia sustentable para becerras de reemplazo de raza Jersey. Tesis M.Sc., Instituto Politécnico Nacional, Altamira, MEX.

Pachón, F., G. Tovar, N. Urbina, y N. Martínez. 2005. Uso de subproductos de caña panelera como suplemento alimenticio para ganado bovino y para evitar la contaminación ambiental. Rev. Med. Vet. Zootec. 52:79-90.

Pádua, F., C. Fontes, J. Almeida, B. Deminicis, L. Almeida, O. Neto, and V. Oliveira. 2014. Fermentation characteristics of silage of sugar cane treated with calcium oxide, Lactobacillus buchneri an their associations. Am. J. Plant Sci. 5:636-646. doi:10.4236/ajps.2014.55078

Pedroso, A.F., L.G. Nussio, D.R. Santana, S.F. Paziani, J.L. Ribeiro, L.J. Mari, and J. Horii. 2008. Fermentation, losses, and aerobic stability of sugarcane silages treated with chemical or bacterial additives. Sci. Agric. 56:589-594. doi:10.1590/ S0103-90162008000600004

Pina, D.S., L.O. Tedeschi, S.C. Valdares, J.A.G. Azevedo, E. Detmann, and R. Anderson. 2009. Influence of calcium oxide level and time of exposure to sugarcane on in vitro and in situ digestive kinetics. Anim. Feed Sci. Technol. 153:101-112. doi:10.1016/j.anifeedsci.2009.06.005 
Ramírez, H., A. Salcedo, E. Briones, F. Lucero, A. Cárdenas, C. Marcof, y J. Martínez. 2014. Rendimiento, caracterización morfólogica y bromatológica de la punta de caña de azúcar en la Huasteca Potosina, México. Rev. Cub. Cienc. Agríc. 48:411-415.

Reyes, J., O. Montañez, C. Guerra, y J. Palma. 2014. Efecto del ensilado de caña de azúcar en los parámetros productivos de vaquillas Holstein-Friesian para reemplazo. Rev. MVZ Córdoba 19:3962-3969.

Reddy, G.V.N, K.J. Reddy, and D. Nagalakshmi. 2002. Effect of expander-extruder processed complete diet containing sugarcane bagasse on growth and nutrient utilization in ongole bull calves. Indian J. Anim. Sci. 72:406-409.

Ribeiro, L.S.O., A.J.V. Pires, B.D. Pinho, G.G.P. Carvalho, e M.A.L. Freire. 2009. Valor nutritivo da cana-de-açúcar hidrolisada com hidróxido de sódio ou óxido de cálcio. Arq. Bras. Med. Vet. Zootec. 61:1156-1164. doi:10.1590/S010209352009000500019

Rodrigues, A. 1999. Cana-de-açúcar como recurso forrageiro para a alimentação de bovinos na época da seca. Embrapa, BRA. https://ainfo.cnptia.embrapa.br/digital/bitstream/CPPSE/13122/1/PROCIAAR2000.00070.pdf (consultado 21 mar. 2019).

Rodríguez, E. 2005. La dextranasa a lo largo de la industria azucarera. Biotecnol. Aplicada 22(1):11-19.

Rodríguez, D., P.C. Martín, F. Alfonso, A.V. Enríquez, y L. Sarduy. 2009. Forraje de caña de azúcar como dieta completa o semicompleta en el comportamiento productivo de toros mestizos Holstein x Cebú. Rev. Cub. Cienc. Agríc. 43(3):231-234.

Rodríguez, D., O. Tuero, y L. Sarduy. 2013. Fuentes de materias primas en el concentrado para evaluar el comportamiento productivo de toros mestizos Holstein alimentados con forraje de caña de azúcar. Rev. Cub. Cienc. Agríc. 47:19-21.

Santos, W., T.M. Carvalho, C.C. Cavalcanti, A.M. Espindola, S.G. Mesquita, A. Neves, y B. Araújo. 2014. Características y estabilidad aeróbica de ensilajes de caña de azúcar, tratada con urea, NaOH y maíz. Pastos y Forrajes 37(2):182-190.

Sierra, O. 1981. Valor nutritivo y utilización de la caña de azúcar y sus subproductos en la alimentación animal. AGROSAVIA, COL. https://repository.agrosavia.co/handle/20.500.12324/22259 (Consultado 8 oct. 2018).

Soarez, M.F., T. Teresinha, R. Dias, A. Ferreira, and J.A. da-Silva. 2012. Metabolism and ruminal parameters of Holstein $\times$ Gir heifers fed sugarcane and increasing levels of crude protein. R. Bras. Zootec. 41:2101-2109. doi:10.1590/S151635982012000900019

Sousa, R.C., R.B. Reis, F.C. Lopez, M.H. Mourther, A.M. Lana, F.A. Barbosa, e B.M. Sousa. 2015. Efeito da adição de teores crescentes de ureia na cana-de-açúcar em dietas de vacas em lactação sobre a produção e composição do leite e viabilidade econômica. Arq. Bras. Med. Vet. Zootec. 67:564-572. doi:10.1590/1678-7799

Suarez, C., C.A. Guevara, E. Carrera, A. Bell, y N. Sánchez. 2016. Formulación de una nueva miel-urea para alimento animal. ICIDCA 50(2):53-57.

Svartz, H., M. Gonzalez, N. Arrigo, y R. Palma. 2005. Bagazo de caña desmedulada: su empleo como sustrato en un cultivo de geranio. Rev. Facultad Agron. 24(2):107-112.

Timana, M., M.G. Echevarría, M.A. Buendía, y A.C. Cordero. 2017. Alimentar con cogollo de caña tratado hace más eficiente los costos de producción de leche en vacuno. Agroindust. Sci. 7(2):67-71. doi:10.17268/agroind.sci.2017.02.02

Torres, J.A. 2011. Alternativas para alimentación de bovinos con base en la caña de azúcar. LAICA, CRC. https://www.laica. co.cr/biblioteca/servlet/DownloadServlet?c=443\&s=2521\&d=32915 (consultado 21 mar. 2019).

Vélez, M., H. Sánchez, y C.V. Duran. 2014. Evaluación de la suplementación energética durante el crecimiento de novillas lecheras de reemplazo utilizando el modelo CNPS. Trop. Subtrop. Agroecosyst. 17:143-154.

Villar, J. 2010. Alimento animal y energía de la caña de azúcar. ICIDCA 43(1):4148.

Zérega, L. 1993. Manejo y uso de la cachaza en suelos cañameleros. Caña de Azúcar 11(2):1-10. 